\title{
0 modelo indexical para o pensamento
}

\author{
* Doutorando pela PUC-Rio \\ phgmuniz@gmail.com
}

PEDRO HENRIQUE GOMES MUNIZ *

RESUMO Diversas teorias já foram elaboradas na tentativa de explicar a semântica dos indexicais. Mais recentemente, especial atenção tem sido dada ao que seriam seus correlatos em um plano estritamente mental. É o caso da teoria dos “arquivos mentais” e “modelo indexical para o pensamento” de François Recanati. Discuto aqui como tal modelo pode ser útil para entender o fenômeno da indexicalidade e a cognição humana de forma geral.

PALAVRAS-CHAVE indexicais, semântica, arquivos mentais, pensamento, cognição.

ABSTRACT Various theories have already been elaborated in the attempt to explain the semantics of indexicals. More recently, special attention has been given to what their correlates should be in a strictly mental level. It is the case of François Recanati's "mental files" theory and his "indexical model for thought". Here I discuss how such a model can be useful to understand the phenomenon of indexicality and human cognition in a general way.

KEYWORDS indexicals, semantics, mental files, thought, cognition.

\section{INTRODUÇÃO}

Herman Cappelen e Josh Dever alcançaram grande notoriedade depois de terem iniciado uma campanha a favor da ideia de que o fenômeno da indexicalidade não seria filosoficamente profundo ou interessante, com a publicação em 2013 de The Inessential Indexical. De forma um tanto paradoxal, podemos encontrar nessa obra pistas para entender porque os indexicais têm ocupado um lugar tão importante nas pesquisas em filosofia analítica das últimas décadas. Como sugerem os autores, em última instância, a questão de fundo sobre os indexicais faz parte da própria história da filosofia ocidental, embora ela ganhe nova roupagem na tradição mais recente que confere uma importância especial para a análise linguística. No fundo, trata-se da questão da representação da realidade a partir de determinada perspectiva, e de como esse perspec- 
tivismo pode ser considerado essencial no sentido de não ser eliminável. Essas perspectivas especiais seriam expressas na linguagem através dos indexicais: por exemplo, “aqui” se refere ao lugar de onde falo, “agora” ao instante no qual falo etc. A questão fica especialmente clara quando pensamos na chamada "perspectiva da primeira pessoa", que é ilustrada por Frege no caso do fenômeno indexical da seguinte forma:

Cada pessoa se apresenta a si mesma de uma maneira peculiar e originária, pela qual não se apresenta a mais ninguém. Assim, quando o Dr. Lauben pensa que foi ferido, ele está se baseando provavelmente nessa maneira originária de se apresentar a si próprio. E só o próprio Dr. Lauben pode apreender os pensamentos assim determinados. Mas suponhamos que ele queira se comunicar com os demais. Ele não pode comunicar um pensamento que só ele pode apreender. Portanto, quando ele diz "Eu fui ferido", ele tem que usar a palavra "eu" em um sentido que possa ser apreendido também pelos demais, por exemplo no sentido de "aquele que lhes está falando neste momento".

Os indexicais (como o pronome "eu") corresponderiam a formas de se expressar na linguagem essas perspectivas especiais (e no caso da primeira pessoa, talvez mesmo a fonte última de todas elas). Mas para além desse perspectivismo, o que realmente caracteriza os indexicais? Na linguagem, é comum dizer que os termos indexicais (também chamados de "dêiticos") são termos cujo valor semântico ou conteúdo varia de acordo com o contexto no qual eles são empregados - eles são sensíveis ao contexto de uso. Alguns exemplos de termos indexicais comuns são: pronomes demonstrativos simples (isto, aquilo etc.) e compostos (este homem etc.); pronomes pessoais (eu, ele etc.) e pronomes possessivos (meu, dele etc.); advérbios de lugar e de tempo (aqui, lá, agora, hoje etc.) e tempos verbais diferentes do presente (estava etc.). Vale a pena chamar atenção para o fato de que a sensibilidade contextual característica dos indexicais é diferente da sensibilidade que observamos em expressões ditas ambíguas, como a palavra "banco" em português, por exemplo. Dependendo do contexto, "banco" pode significar um objeto usado para se sentar, uma instituição financeira ou ainda ser usado em expressões como "banco de dados". No caso dos indexicais, sua suposta “ambiguidade” provém do próprio significado da palavra, do que podemos chamar de seu significado linguístico . Costuma-se dizer que, no caso de um indexical, seu significado linguístico reflete a relação que deve existir entre a instância do indexical em questão e sua referência no contexto no qual o indexical é empregado. Tal significado é a expressão da regra 
dessa relação. Por exemplo, no caso do pronome pessoal da primeira pessoa “eu”, seu significado seria algo como "refere-se ao indivíduo que expressa a proposição". Esse é o significado "fixo" de um indexical, sendo "fixo" no sentido de que o aprendemos quando aprendemos a usar o próprio indexical. A existência desse nível de significado explica porque somos capazes de entender de alguma forma o que significam os indexicais mesmo que eles não sejam usados em contexto algum. Um falante competente de português entende o que significa a palavra "aqui", por exemplo, mesmo que ele esteja fora de um contexto de uso.

Pela extensão do fenômeno, é claro que os indexicais são expressões que ocupam um lugar de destaque em nossos discursos. Não é surpreendente que muitas tentativas de explicar a semântica desses termos já tenham sido feitas pelos mais diversos teóricos da linguagem. Talvez seja natural que a maioria deles tenha enxergado o fenômeno como realmente próprio a filosofia da linguagem em um sentido mais estrito: como um fenômeno que tem como seu limite a esfera da linguagem. Talvez a proposta mais bem aceita atualmente seja a que tem suas origens nas ideias de David Kaplan. Na verdade, ao me referir ao que chamei de "significado linguístico" de um indexical, de certa forma já comecei a tratar da proposta kaplaneana. A teoria semântica de Kaplan é tripartida, nela temos três níveis: o nível do próprio signo, da palavra; o nível do que chamei de "significado linguístico" público, que Kaplan chama de “caráter” (character); e o nível do próprio referente do signo, a entidade que é denotada pelo signo, que Kaplan chama de "conteúdo" (content) - Apesar da tripartição existir tanto na teoria fregeana quanto na teoria kaplaneana, para Kaplan a referência de um signo ocorre de maneira direta, pois o que ele chama de "caráter" apenas dita uma regra (estabelecida pelas convenções da linguagem) de aplicação do signo de acordo com o contexto - assim, uma vez que a regra é aplicada, o signo se liga a seu referente de forma direta.

A tripartição signo-caráter-conteúdo deve naturalmente poder ser aplicada a todas as expressões linguísticas. Mas o caráter de um indexical é especial no sentido de poder fornecer um novo referente/conteúdo dependendo do contexto de uso, o que não acontece com outras expressões linguísticas, como nomes próprios, por exemplo. O nome próprio de determinado indivíduo fornece o mesmo referente em qualquer contexto, e assim acontece para todas as expressões não-indexicais. Por isso dizemos que indexicais são sensíveis ao contexto. O caráter reflete (na forma de uma regra) as rela- 
ções que devem existir entre o signo e seu conteúdo no contexto em que o signo ocorre. É nesse sentido que os indexicais refletem suas ocorrências. Em inglês, diz-se que indexicais são token-reflexive: “token” significa “ocorrência”, "instância” ou “exemplar”. Tal é, em linhas gerais, uma das formas de explicação do funcionamento dos indexicais na linguagem comum mais bem aceitas na filosofia contemporânea. Mas este modelo de explicação da semântica dos indexicais é puramente linguístico. Como o próprio Kaplan deixa claro em “Demonstratives”, seu projeto não trata nem mesmo das intenções do falante ao usar indexicais, mas tão somente do significado linguístico objetivo. Sua teoria não é sobre o "significado do falante" (speaker's meaning), mas sim sobre o significado linguístico. Mais recentemente, no entanto, tem-se feito algumas tentativas no sentido de demonstrar que os indexicais têm correlatos também em um plano estritamente mental. Defende-se a necessidade de se desenvolver uma teoria para explicar essa indexicalidade mental, e questiona-se se seria possível tomar como base o atual modelo linguístico do qual dispomos (esboçado acima) para desenvolver um novo modelo, não para a linguagem, mas para o pensamento. É o que tenta fazer Recanati, através da metáfora dos arquivos mentais.

\section{A TEORIA dOS ARQUIVOS MENTAIS E O MODELO INDEXICAL PARA O PENSAMENTO}

Um dos mais notáveis e controversos exemplos desse movimento recente é a teoria dos “arquivos mentais” de François Recanati. Claramente influenciado por John Perry, Recanati faz uso da noção de arquivos mentais para explicar (ou ilustrar, pois se trata de uma metáfora), dentre outras coisas, como o conhecimento sobre os objetos que encontramos em nossa experiência cognitiva é adquirido, armazenado, manipulado ou reutilizado.

Para ele, nossa vida mental funciona tendo como base mecanismos similares a arquivos. Criamos diferentes tipos de "arquivos mentais" dependendo do tipo de relação de ganho epistêmico (epistemically rewarding relation) que temos com determinado objeto. Relações indexicais são relações epistêmicas muito específicas, mas para Recanati, elas também podem ser explicadas dentro de sua teoria - especificamente com a ajuda do que ele próprio chama de "modelo indexical para o pensamento".

Quais são as principais ideias por trás da metáfora dos “arquivos mentais"? Recanati escreve que são as seguintes: 1 . Um sujeito encontra durante sua vida cogni- 
tiva vários objetos e entra em relações diversas com eles; 2. Algumas dessas relações são de familiaridade (em inglês, acquaintance, um termo que herdamos de Bertrand Russell): quer dizer que são diretas e envolvem um ganho epistêmico; 3. O papel de um arquivo mental baseado em uma relação de familiaridade (acquaintance) é armazenar informação adquirida em virtude dessa relação; e 4. Arquivos baseados em relações de familiaridade são temporários - existem apenas enquanto as relações existem. A noção (originalmente russelliana) de familiaridade é importante ao aplicarmos a teoria dos arquivos mentais à explicação de uma suposta indexicalidade mental porque "pensar indexicalmente" teria que envolver uma relação direta como a de familiaridade.

Quando um sujeito está percebendo determinado objeto com seus sentidos - seguindo-o com o olhar, por exemplo -, ele é capaz de pensar em tal objeto demonstrativamente, talvez como em “Aquela montanha é linda!”. Este é apenas um caso especial de indexicalidade. Para Recanati, esse modo específico de pensar só perdura enquanto o sujeito estiver percebendo o objeto, pois pensar demonstrativamente sobre um objeto envolve a ativação de um arquivo mental que é temporário, já que depende da relação perceptiva, a qual eventualmente será interrompida. O que o próprio Recanati escreve sobre este ponto é interessante: “Quando a relação é quebrada, o arquivo temporário baseado nela desaparece. (A informação no arquivo não é perdida, é claro, mas transferida para outros arquivos)".

Grosso modo, o esquema de Recanati da criação de arquivos mentais demonstrativos/indexicais e do subsequente reaproveitamento da informação armazenada em tais arquivos pelo sujeito pensante poderia ser explicado da seguinte forma. No caso de um pensamento demonstrativo, tanto o próprio pensamento quanto o arquivo mental correspondente parecem depender na existência de uma relação perceptual adequada. Em relação de dependência estão também o pensamento demonstrativo e o arquivo mental criado, aquele dependendo deste para existir.

Uma vez que o sujeito sai do contexto no qual está sustentando uma relação perceptual com o objeto em questão, um quadro semelhante ao seguinte configurar-se-ia: o pensamento demonstrativo cessa de existir, cessando também a existência do arquivo demonstrativo recentemente criado, pois a existência de um depende da existência do outro, de forma recíproca. A informação armazenada no arquivo de- 
monstrativo não é perdida - ela é, segundo a teoria, transferida para um novo arquivo mental, de um tipo cujo tempo de vida é mais longo - são os chamados "arquivos enciclopédicos” ou “arquivos estáveis".

Como Recanati usa os arquivos mentais para explicar a indexicalidade no nível do pensamento? A noção de significado linguístico convencional que na teoria de Kaplan é representada pela noção de caráter não pode ser aplicada no plano mental. Arquivos mentais não são classificados em "tipos” de acordo com um significado estabelecido por convenção, como são expressões linguísticas . No entanto, para Recanati, descobrimos o tipo de um arquivo mental ao descobrirmos o tipo de relação de ganho epistêmico que ele explora. Por exemplo, sou capaz de ter determinados pensamentos sobre mim mesmo por poder ter algumas relações específicas de ganho epistêmico comigo mesmo e através delas armazenar informações em um tipo de arquivo específico: o arquivo do self.

Podemos identificar duas importantes motivações para a aplicação de um modelo indexical ao pensamento, nos moldes do que é proposto por Recanati. Em tal modelo, 1. A distinção entre tipo e ocorrência se aplica também ao pensamento; e 2. As relações contextuais desempenham um papel importante tanto no nível do pensamento quanto no nível da linguagem. A ideia é que, assim como um termo indexical, quando um tipo de arquivo mental ocorre, tal ocorrência explora relações contextuais específicas para se referir a alguma entidade na realidade. Para a aplicação do modelo indexical ao pensamento, há uma substituição do papel funcional do significado linguístico (o caráter, em Kaplan), mas a característica essencial da centralidade do papel do contexto é preservada, da mesma forma que a distinção entre tipo e ocorrência.

\section{CONSIDERAÇÕES FINAIS}

Acredito que um dos pontos fortes da proposta de Recanati está em uma de suas motivações: sua defesa da ideia de que a indexicalidade não está restrita ao nível linguístico do conteúdo, que não se trata de um fenômeno que pertence apenas a linguagem. Como sugeri ao falar brevemente de Cappelen e Dever, embora eles defendam uma opinião exatamente oposta, talvez o fenômeno da indexicalidade tenha sua verdadeira origem na cognição humana, no plano mental e epistêmico, não sendo um fenômeno apenas linguístico. A despeito de possíveis problemas da proposta de Recanati, o 
modelo indexical para o pensamento nos fornece intuições úteis para a explicação do funcionamento de áreas importantes da nossa cognição. Além de ajudar na compreensão de nossos mecanismos epistêmicos em geral, a metáfora dos arquivos mentais poderia ser útil para entendermos, por exemplo, como conceitos são adquiridos e como nossa relação com eles evolui com o tempo.

\section{REFERÊNCIAS}

CAPPELEN H.; DEVER, J. The Inessential Indexical: On the Philosophical Insignificance of Perspective and the First Person. Oxford: Oxford University Pres, 2013.

FREGE, G. “O Pensamento. Uma investigação lógica”. Trad. Paulo Alcoforado. In: Investigações Lógicas. Porto Alegre: EDIPUCRS, 2002, p. 9-39.

KAPLAN, D. "Demonstratives: An essay on the semantics, logic, metaphysics, and epistemology of demonstratives and other indexicals”. In: ALMOG, J.; PERRY, J.; WETTSTEIN, H.. (Ed.) Themes from Kaplan. Oxford: Oxford University Press, 1988, p. 481-563.

LEWIS, D. “Attitudes De Dicto and De Se”. In: Philosophical Review. LXXXVIII/4 (1979), p. 513-543.

NUNBERG, G. "Indexicality and Deixis”. In: Linguistics and Philosophy. XVI (1993), p. 1-43. PERRY, J. “Frege on Demonstratives”. In: Philosophical Review. LXXXVI/4 (1977), p. 474-497. . “The Problem of the Essential Indexical”. In: Nô̂s. XIII/1 (1979), 3-21. . “'Borges and I' and 'I’”. In: The Amherst Lecture in Philosophy. II (2007), p. 1-16. RECANATI, F. Singular “Thought: In Defence of Acquaintance”. In: JESHION, R. (Ed.) New Essays on Singular Thought. Oxford: Oxford University Press, 2010, p. 141-189. RECANATI, F. Mental Files. Oxford: Oxford University Press, 2012. 